\title{
MISCELÁNEA
}

\section{RANCHO 'VIVIENDA RURAL O FINCA DE CAMPO': UN ANDALUCISMO LÉXICO MÁS DEL ESPAÑOL DE AMÉRICA}

\author{
Juan A. Frago Gracia
}

1. Afirma Corominas que "en los siglos Xvi y xvir rancho era palabra bien conocida en todos los paises donde se ha hablado castellano, designando toda clase de viviendas provisionales $[\ldots]$. Era sobre todo una palabra de soldados, y éstos la aplicaron a las chozas y guaridas de los indios americanos, de donde quedó luego como nombre de vivienda pobre y rural de los habitantes de América, aun los criollos", y añade que "al uso americano contribuirian los marinos, dada la gran importancia del influjo náutico en el habla americana, pero fue sobre todo a los soldados conquistadores del Nuevo Mundo a quienes cupo la mayor parte en la difusión y arraigo de este vocablo en América, que es donde hoy conserva mayor vitalidad, desde el Cabo de Hornos hasta los Estados Unidos" '. En cuanto al origen del vocablo, bien sabido es que el filólogo catalán lo considera derivado de rancharse o ranchearse 'alojarse', término soldadesco préstamo del francés, mientras que $\mathrm{H}$. Meier se inclina por atribuirle naturaleza castellana, aunque a mí me interesa ahora, más que el debatido problema etimológico, dejar sentada la opinión de aquel autor, admitida por muchos otros, en el sentido de que la acunación semántica de rancho en el continente indiano comparte la impronta militar y marinera ${ }^{2}$.

1 J. Corominas, con la colaboración de José A. Pascual, Diccionario crítico etimológico castellano e bispánico [DECH], Madrid, Gredos, 1980-1991, s. v. rancho. A esta entrada se referirán todas las menciones de Corominas que se hagan a continuación mientras no se indique otra cosa.

2 Un buen número de noticias sobre el particular acopia Mariano Franco Figueroa en «Léxico marinero en documentos americanos del s. xVI y xVII: marinerismos o voces que designan realidades terrestres», Anuario de Lingüística Hispánica, IV, págs. 170-171. 
Americana es principalmente la caracterización documental de este vocablo, y del sufijado ranchería, con una primera datación de hacia 1535 en el $D E C H$, de 1530 en el estudio de Franco Figueroa y de 1532 en los materiales allegados por Boyd-Bowman ${ }^{3}$. Y, si la trayectoria histórica de rancho con referencia significativa de 'vivienda rural o finca de campo' está profusamente fijada en fuentes textuales del Nuevo Mundo, su descripción en la sincronia actual muestra una notable correspondencia con el anterior hecho: se trata, efectivamente, de un americanismo general, aunque con diversas acepciones en la geografía lingüística del otro lado del Atlántico. Pero, si bien se mira, su misma variación semántica, hasta llegar al rioplatense 'sombrero de paja', igual que su diferenciación léxica a través del procedimiento de la sufijación (ranchada, ranchería, rancherio, ranchero, ranchita, ranchón $)^{4}$, son evidentes muestras $\longrightarrow$ consecuencias, si se quiere- del profundo enraizamiento y de la vitalidad del elemento nominal simple en la América española.

2. Sin embargo, ese perfecto paralelismo entre pasado y presente del uso de rancho en España no está igualmente determinado, ni tampoco se ha concretado debidamente la relación inicialmente existente entre el español peninsular y el americano en lo tocante a dicha cuestión léxica. Más allá de lo que es mera hipótesis de principio, muy poco, por no decir nada, se sabe al respecto, lo cual no deja de sorprender en una voz considerada por tantos americanistas y habida cuenta de que en puridad metodológica este es un punto que requiere aclaración, dado que el vocablo de referencia era de inmediata ascendencia hispánica. Debe saberse, y no sólo suponerse, si antes del descubrimiento de América estaba extendido por todo el dominio castellano o nada más que en una parte de él, pues así se explicará mejor su rápida implantación a lo largo y a lo ancho del mundo indiano. No será superfluo conocer también los perfiles significativos de rancho previos a su travesía atlántica, porque en caso contrario será difícil afirmar fehacientemente su casi instantánea diferenciación semántica apenas aclimatado en las nacientes comunidades americanas.

Pues bien, el $D R A E$ únicamente registra tres acepciones directamente relacionadas con el sentido básico de 'vivienda rural', a saber: 'choza o casa pobre con techumbre de ramas o paja, fuera de poblado' (general), 'finca de labor de menos extensión que el cortijo y por lo común con vivienda' (andaluz) y 'granja donde se crían caballos y otros cuadrúpedos' (americano), a

3 Peter Boyd-Bowman, Léxico bispanoamericano del siglo XVI, London, Tamesis Books, 1971 [Madrid, 1972], págs. 779-780.

4 Véanse las correspondientes entradas en Marcos A. Morínigo, Diccionario de Americanismos, Barcelona, Muchnik Editores, 1985, s. vv. 
las cuales seguramente habría que añadir, si no es una redundancia de la consignada aqui en primer lugar, la de 'lugar fuera de poblado, donde se albergan diversas familias o personas (rancho de gitanos, de pastores)', también dada como de uso común, igual que la definición única de ranchería, 'conjunto de ranchos o chozas que forman como un lugar' 5 . Pero, ¿quién corroborará la exactitud de esta última información lexicográfica, ni avalará la caracterización diatópica de la misma generalidad propuesta a las dos acepciones de rancho ya vistas? Es excepcional el caso de un vocabulario regional que, como el de Iribarren, conozca este tipo léxico con la configuración semántica que nos ocupa, y aun asi dicho autor no lo hace extensivo a toda Navarra, sino que lo encuentra limitado a un par de enclaves pirenaicos: 'corral separado de la casa' (Roncal) y 'cuadra o corral donde encierran a las ovejas para esquilarlas' (Salazar) ${ }^{6}$. $\mathrm{Ni}$ que decir tiene que la perspectiva cambia radicalmente si se mira al sur, pues Alcalá Venceslada acopia nada menos que las siguientes verificaciones sobre el particular: ranchal 'terreno de monte quemado'; ranchero 'individuo que prepara la leña para hacer carbón', 'dueño o colono de un rancho'; rancho 'cortijillo', 'raso, espacio libre y despejado de terreno', 'delantera de la casa de una huerta', 'lugar donde se carbonea' ?.

De hecho, Corominas aduce una mención del Guzmán de Alfarache, según la cual podría "ya tratarse del uso moderno de Andalucia, donde, quizá por el íntimo contacto con América, el vocablo ha tomado raiz fija hasta nuestros dias, siendo el nombre de la 'hacienda rústica', por ejemplo en la provincia de Cádiz [...] ; también logró cierto arraigo, con sentidos especiales, en Aragón ('esquiladero' Borao), Salamanca (ranchera 'lumbrarada que se hace en majada o chozo' Lamano). Pero la mayor rareza de estos testimonios y en buena parte su fecha moderna, muestran ya que todo esto es secundario" 8 . Curiosa argumentación, como se ve, pues ¿con qué se relacionan los testimonios norteños de rancho 'habitáculo rústico'? ¿con los usos andaluces o con los americanos o, por el contrario, con la base léxica hispánica de un periodo anterior a los viajes colombinos? El criterio de la fecha moderna no es en modo alguno convincente, porque recientes son sólo los inventarios de palabras regionales de donde se han sacado esos datos, mas ello no autoriza a conceder la misma modernidad a los elementos léxicos en cada uno de ellos

\footnotetext{
5 Real Academia Española, Diccionario de la lengua española, Madrid, Espasa-Calpe, 1984, vigésima edición, s. vv.

- José M. Iribarren, Vocabulario navarro, segunda edición preparada y ampliada por Ricardo Ollaquindia, Pamplona, Institución Príncipe de Viana, 1984, s. v. rancho.

7 Antonio Alcalá Venceslada, Vocabulario andaluz, Madrid, Gredos, 1980, reimpresión, s. vv.

8 Corominas cita otro pasaje de Mateo Alemán en el que rancho es de uso marinero, dato que quizá haya que relacionar con la referencia sincrónica de la nota 16.
} 
acopiados. Y, puestas así las cosas, es necesario volver la mirada hacia el momento en que tiene lugar el paso de nuestro término a América.

3. Para empezar, la negación que antes he formulado en contra de la vigencia en la completa extensión del español actual de ranchería y de dos de las reseñadas acepciones de rancho, tal y como en el $D R A E$ se propone, de alguna manera viene refrendada por la primera edición del diccionario académico, ya que en la entrada de la palabra simple no hay alusión al sentido que fundamentalmente nos interesa, aunque su presencia se descubra en la definición de ranchería 'el sitio, paraje o casa en el campo donde se recoge la gente de un rancho, de cuya voz se forma', y no debe ser casual que la autoridad que para la inclusión de esta voz se esgrime sæa precisamente la de un texto cronístico ${ }^{9}$. No obstante, frente a esa escasa familiaridad, cuando no desconocimiento absoluto, que con ranchería y rancho demuestran las fuentes lexicográficas del $\mathrm{xvIII}{ }^{10}$, un escritor malagueño en 1784 proporcionará citas como éstas:

Jaced unas cachorreñas;
vamos al rancho
él allá se las jar[r]ee,
que yo me retiro al rancho
Jacob. los dos migaremos,
trae tú la saltén del rancho
a.............................
yarraron a la helmana,
y al rancho se la trujeron,
no como de allí salió,
cuando coriosa al paseo
jue a buscar su peldiciónn ${ }^{11}$.

En dichos pasajes se verifica que rancho es la cabaña del pastor, pero asimismo vivienda familiar de los de este oficio. Y en 1618 el rondeño Vicente Espinel recurriría al empleo de rancho con el significado de 'campa-

- Real Academia Española, Diccionario de Autoridades, Madrid, Gredos, 1969, edición facsímil de la de $1726-1739$, s. vv. El texto citado es del P. Bartolomé Alcázar, autor del siglo xvIr.

10 Por ejemplo, aunque Esteban de Terreros y Pando recoge rancheria con definición muy parecida a la del Autoridades y reúne algún nuevo sentido bajo rancho, continúa sin dar a este vocablo su aceptación de 'vivienda rural' en el Diccionario castellano con las voces de ciencias $y$ artes..., Madrid, Arco/Libros, 1987, edición facsímil de la de 1786-1793, s. vv.

11 Gaspar Fernández y Ávila, La infancia de Jesu-Cbristo, edición y estudio por Francisco Torres Montes, Granada, Universidad de Granada, 1987, págs. 124, 137, 154, 173. 
mento o cobijo provisional': "No tomáuamos puerto para lo necessario sino en las riberas que más cómodas parecían para assentar el rancho" ${ }^{12}$. Y enlazamos asi con el testimonio cronológicamente precedente de Mateo Alemán, en opinión de Corominas explicable por el estrecho contacto que a la sazón mantenían Andalucía y América. Pero, ¿ efectivamente el valor semántico que ese registro textual manifiesta era de ascendencia indiana? Inicialmente hay que decir que ni siquiera se ajusta al sentido andaluz de 'cortijillo', como en el $D E C H$ se aventura, y una detenida lectura de las siguientes líneas del Guzmán de Alfarache inmediatamente pondrá de relieve que en ellas rancho a lo sumo significa 'refugio provisional', acepción igual o muy próxima a la que Vicente Espinel emplea:

Desta manera me entretuve en tanto que desmentí las espias y cuadrilleros que sin duda debieron de ir tras de mí. Así se perdió el rastro. Y pareciéndome que todo estaría seguro para poder mudar el rancho y marchar, hice un pequeñuelo lifo de los forros viejos que del sayuelo me quedaron, donde metí envuelta la sangre de mi corazón ${ }^{13}$.

Desde luego la fortuna no acompañó a Corominas mientras redactaba el artículo etimológico rancho, porque tampoco se puede admitir sin más que sea en el Nuevo Mundo donde esta voz "conserva mayor vitalidad", aseveración que sería cierta sólo teniendo en cuenta la totalidad del dominio español peninsular en contraste con el americano, y aún habría que ver si en buena parte de España alguna vez la tuvo, cosa que muy seriamente dudo. Pero en hablas de Andalucía occidental también presenta rancho una importante implantación, pues, además de las noticias acopiadas por Alcalá Venceslada, con el sentido de 'finca de labor, generalmente con casa, de menor importancia que el cortijo', lo he recogido en las localidades sevillanas de Alcalá de Guadaira, Coripe, Écija, El Coronil, Estepa, Gerena, Las Cabezas de San Juan, Lebrija, Marchena y Utrera; en las gaditanas de Chipiona, Olvera, Tarifa, Ubrique y Villamartín; y en la onubense de Cartaya. Con la particularidad de que en todos estos lugares el vocablo tiene también uso toponímico, y ello de por sí es un aval de su tradicional arraigo ${ }^{14}$.

12 Vicente Espinel, Relaciones de la vida del escudero Marcos de Obregón, edición facsímil, Real Academia Española y Caja de Ahorros de Ronda, Málaga, 1990, pág. 148a.

13 Este es el fragmento textual al que alude Corominas, de la edición de Samuel Gili y Gaya, Madrid, Clásicos Castellanos, 1928, t. II, pág. 109.

14 He aquí un breve expurgo de mis materiales onomásticos: Rancho del Refugio, Rancho Colorado (Alcalá de Guadaira), Rancho de las Víboras, Rancho Mayorazgo (Coripe), Rancho de la Orden (Écija), Rancho Higuerita, Rancho Largo (El Coronil), Rancho del Tuerto, Rancho la Cruz (Estepa), Cortijo el Rancho (Gerena), Rancho de las Ortigosas, Rancho de los Oteros (Las Cabezas de San Juan), Rancho de las Cruces, Rancho Prado (Lebrija), Rancho Grande, Rancho de Vargas (Marchena), El Rancho (Utrera), Rancho de la Copina (Chipiona), Rancho Correa, Rancho del Toconal (Olvera), Rancho 
4. Hasta dónde llegue la antigüedad de rancho en Andalucia con un significado que lo relacione con su vigencia americana, eso es algo que sólo la documentación, como siempre, será capaz de desvelar. Y dos pasajes de las Ordenanzas de Carmona, copiadas en 1511 de otras de 1495, vienen a anticipar mucho la fijación de nuestro término en el mapa andaluz:

e que todas las personas que anduvieren por los dichos montes puedan cojer e llevar a sus casas del canpo o ranchos de la dicha leña quemadiza para quemalla [...]. Y el que tuviere yesca o eslabón en casas pagizas o en sus ranchos o hatos, que tenga la dicha pena ${ }^{15}$.

$\mathrm{Ni}$ que decir tiene, la mera datación en los comienzos del siglo xvi autoriza a rechazar cualquier implicación de un reflujo indiano en este caso. Al revés, estamos asi seguros de que con la acepción de 'vivienda rural' ya fue llevado rancho a las Indias por el flujo de los conquistadores y colonizadores españoles, incluidos los marineros, pero no los de todas las regiones peninsulares, sino exclusiva o principalmente los naturales de Andalucía. Se restituye tambièn la coherencia lingüística e histórica en este problema de diacronía léxica, pues no dejaba de resultar chocante el hecho de que habiendo sido rancho "palabra bien conocida en todos los países donde se ha hablado castellano, designando toda clase de viviendas provisionales" y habiendo sido trasladada al Nuevo Mundo por "los soldados conquistadores", como Corominas afirma, no se adujera referencia documental alguna que no fuera de procedencia indiana: ¿tan extendido había estado rancho en España, y no se hallaba registrado en ninguna parte antes del descubrimiento con cualquiera de sus acepciones?

No puedo entrar, entre otras cosas porque no dispongo de argumentos suficientemente válidos para ello, en la discusión de si esta voz es de origen francés o castellano, o de si verdaderamente está enraizada desde el principio en la terminología soldadesca, como tampoco podría asegurar si su significado marinero fue antes que el terrestre, o a la inversa, aunque sí sé que en la actualidad todos los puntos costeros encuestados en el $A L E A$ la recogen como término usual entre los marinos ${ }^{16}$. Y todavía queda por aclarar el

de la Cerca, Rancho de la Herradura (Tarifa), Rancho del Acebuche, Rancho del Conde (Ubrique), Rancho Lobreyuete, Rancbo Perdiz (Villamartín), Rancho Juan Pérez (Cartaya). Incluso en el Parque Nacional de Doñana hay un paraje llamado Rancho de María Manuela.

15 Ordenanzas del Concejo de Carmona, edición y estudio preliminar por Manuel González Jiménez, Sevilla, 1972, págs. 71, 74. Según este medievalista, el manuscrito en que nos ha llegado el ordenamiento concejil es de 1525-1535.

18 Véase Manuel Alvar, con la colaboración de A. Llorente y G. Salvador, Atlas lingüístico y etnográfico de Andalucia, Universidad de Granada, C.S.I.C., 1961-1973, mapa 1070. 
porqué de su peculiarismo meridional, aquí el recurso al sustrato mozárabe se viene a la mano con peligrosa facilidad, igual que se deberá justificar la presencia de dicho tipo léxico-semántico en unas pocas hablas norteñas, según lo que hasta ahora sobre el particular se sabe. $\mathrm{Y}$ en principio no descartaría que tales casos se debieran al papel ejercido por la trashumancia ganadera en las migraciones léxicas, pues siempre han sido los pastores del norte quienes han buscado la invernada en el sur, y no al contrario, si bien asimismo hay que contar con la posibilidad de que en la Edad Media desde Asturias y León hasta Andalucía bajara rancho como un occidentalismo léxico más. Pero hay que aguardar al dictamen documental sobre la antigüedad de la forma salmantina mencionada en el $\mathrm{DECH}{ }^{17}$.

Ahora bien, es razonable creer en la precedencia andaluza del uso americano de rancho, y si Corominas sostuvo una tesis opuesta a la que yo defiendo fue porque no había hallado la clave textual del enigma, y también porque se dejó guiar por el postulado excesivamente rígido de que casi todas las coincidencias andaluzas y americanas en materia de vocabulario son fruto de "convergencias recientes", de acuerdo con un planteamiento histórico, tan rotundo como falso, que publicó pronto hará medio siglo ${ }^{18}$. Ocurrió con rancho igual que con alfajor, estero o maceta, voces que desde Andalucía pasaron a América y alli pronto cobraron por doquier carta de naturaleza. Su americanismo consiste, precisamente, en la generalización lograda en la completa extensión del continente indiano de lo que era un hecho regional en España, así como en las especializaciones y variaciones léxico-semánticas experimentadas en su nuevo destino geográfico y social.

17 Probablemente conecte al mencionado uso navarro y aragonés de rancho con la trashumancia, y en consecuencia con su presumible procedencia andaluza, la existencia en la localidad soriana de Olvega, contigua a Aragón, de la locución estar de rancho con el significado de '(estar de) esquileo': Manuel Alvar, con la colaboración de A. Llorente, T. Buesa y Elena Alvar, Atlas lingüistico y etnográfico de Aragón, Navarra y Rioja, Madrid, Editorial La Muralla, 1979-1983, mapa 614.

$18 \mathrm{~J}$. Corominas, «Indianorrománica. Occidentalismos americanos», Revista de Filología Hispánica, VI, 1944, pág. 140. En realidad, este investigador niega tajantemente la existencia del dialecto andaluz en los siglos xvi y xvir. 